\title{
A Comparison of Leak Compensation During Pediatric Noninvasive Ventilation: A Lung Model Study
}

\author{
Jun Oto MD PhD, Christopher T Chenelle, Andrew D Marchese, \\ and Robert M Kacmarek PhD RRT FAARC
}

\begin{abstract}
BACKGROUND: Ventilators used for noninvasive ventilation (NIV) must be able to synchronize in the presence of system leaks. We compared the ability of 7 ICU ventilators and 3 dedicated NIV ventilators to compensate for leaks during pediatric NIV. METHODS: Using a lung simulator, we compared the Maquet Servo-i, Dräger V500, Dräger Carina, Covidien PB840, Respironics V60, Respironics Vision, GE Healthcare/Engström Carestation, CareFusion Avea, Hamilton C3, and Hamilton G5 during increasing $(n=6)$ and decreasing leaks $(n=6)$. With a lung simulator we tested 4 leak levels (baseline [BL] 2-3 L/min, L1 5-6 L/min, L2 9-10 L/min, and L3 19-20 L/min); 3 patient weights $(10,20$, and $30 \mathrm{~kg}$ ); and 3 lung mechanics scenarios (normal, obstructive, and restrictive). The ventilator settings were NIV mode, pressure support of $10 \mathrm{~cm} \mathrm{H}_{2} \mathrm{O}$, and PEEP of $5 \mathrm{~cm} \mathrm{H}_{2} \mathrm{O}$. The synchronization rate (synchronized cycles/total simulated respirations) was recorded for each ventilator and each leak scenario. Synchronization was defined as triggering without auto-triggering, miss-triggering, delayed cycling, or premature cycling. RESULTS: The mean synchronization rate across all ventilators was $68 \pm 27 \%$ (range 23-96\%) and marked differences existed between the ventilators $(P<.001)$. Significant differences in synchronization rate were observed between the 10-kg model (mean $57 \pm 30 \%$, range $17-93 \%$ ), the $20-\mathrm{kg}$ model $(69 \pm 30 \%, 25-98 \%)$, and the 30-kg models $(77 \pm 22 \%, 28-97 \%)(P<.001)$. The synchronization rate for the obstructive model $(60 \pm 30 \%, 9-94 \%)$ was significantly different from the normal model $(71 \pm 29 \%, 18-98 \%)$ and the restrictive model $(72 \pm 28 \%, 23-98 \%)(P<.001)$. The PB840 and the $\mathrm{C} 3$ had synchronization rates over $90 \%$ overall across all body weights, all lung mechanic profiles, and all leak levels. CONCLUSIONS: Leak compensation in NIV for pediatric use can partially compensate for leaks, but varies widely among ventilators, patient weights, and lung mechanics. Key words: leak compensation; pediatric noninvasive ventilation; acute care ventilator. [Respir Care 2014;59(2):241-251. (C) 2014 Daedalus Enterprises]
\end{abstract}

\section{Introduction}

Noninvasive ventilation (NIV) has been used as a treatment for acute and chronic respiratory failure in adults ${ }^{1}$ and children. ${ }^{2}$ In adult patients, high-level evidence supports the use of NIV in cardiogenic pulmonary edema,

\footnotetext{
The authors are affiliated with Respiratory Care Services, Massachusetts General Hospital, Boston, Massachusetts.

This study was partly supported by Covidien. Dr Kacmarek has disclosed relationships with Maquet and Covidien. The other authors have disclosed no conflicts of interest.

Supplementary material related to this paper is available at http:// www.rcjournal.com.
}

exacerbation of COPD, neuromuscular disorders, and respiratory distress in the immuno-compromised patient. ${ }^{1}$ Although the application of NIV for pediatric patients is less established than for adult patients, NIV is considered acceptable in children with severe obstructive sleep apnea syndrome,${ }^{3}$ post-extubation respiratory failure, ${ }^{4,5}$ immunocompromised acute respiratory failure, ${ }^{6}$ and chronic respi-

\footnotetext{
Correspondence: Robert M Kacmarek PhD RRT FAARC, Respiratory Care Services, Massachusetts General Hospital, 55 Fruit Street, Boston MA, 02114. E-mail: rkacmarek@partners.org.
}

DOI: $10.4187 /$ respcare. 02616 
ratory failures such as neuromuscular disease ${ }^{7}$ and cystic fibrosis. ${ }^{8}$

While NIV theoretically allows for respiratory system muscle unloading, alveolar recruitment, oxygenation, and $\mathrm{CO}_{2}$ wash-out, patient-ventilator asynchrony is a major issue leading to NIV treatment failure. ${ }^{9}, 10$ There are many ventilators available for NIV for children, but particularly in small children, triggering and cycling problems occur frequently. ${ }^{10}$ Pediatric patients with respiratory failure may develop an extreme breathing pattern with higher breathing frequencies and small tidal volumes, leading to an inability to achieve sufficient inspiratory flow to trigger a breath. ${ }^{11}$ In addition, gas leaks around the mask lead to auto-triggering, miss-triggering, and delayed cycling. ${ }^{11,12}$ Essouri et al reported that triggering asynchrony occurred in $33 \%$ of patients studied, with auto-triggering and misstriggering occurring in up to $38 \%$ and $20 \%$ of total patient breaths, respectively. ${ }^{9}$ Fauroux et al performed a bench study to evaluate the response of 17 home care ventilators in 6 pediatric profiles. ${ }^{10}$ None of the tested ventilators adequately ventilated the 6 pediatric profiles, mainly due to insufficient trigger sensitivity. ${ }^{10}$

Recently, manufacturers have implemented leak compensation on the latest acute care ventilators, to compensate for and better manage leaks. In adult settings, some bench studies assessing leak compensation have shown improved triggering and cycling synchronization, but with wide variation among ventilators. ${ }^{13,14}$ To the best of our knowledge, there have been no assessments of leak compensation during pediatric NIV. The goal of this study was to evaluate the ability of acute care ventilators to prevent triggering and cycling asynchrony in the presence of leaks during pediatric NIV.

\section{Methods}

Seven ICU ventilators (Maquet Servo-i, Covidien PB840, Hamilton C3, Hamilton G5, GE Healthcare/ Engström Carestation, Dräger V500, and CareFusion Avea) and 3 dedicated NIV ventilators (Respironics V60, Respironics BiPAP Vision, and Dräger Carina) were compared, using a lung simulator (ASL5000, IngMar Medical, Pittsburgh, Pennsylvania) with increasing and decreasing system leaks (Table 1). The ASL5000 is a computerized lung simulator consisting of a piston moving inside a cylinder. ${ }^{15}$ It incorporates a series of 3 user-controlled leaks with a Simulator Bypass and Leak Valve Module (IngMar Medical, Pittsburgh, Pennsylvania). Gas leak is created at the airway opening of the lung simulator by 3 different orifice sizes, and is nonlinearly related to pressure and flow. Compliance, resistance, and the inspiratory muscle pressure profile (negative pressure created by respiratory muscles) are set by the user. Each ventilator was connected to the lung simulator by the manufacturer's stan-

\section{QUICK LOOK}

\section{Current knowledge}

One element of success with noninvasive ventilation (NIV) is the ventilator's ability to trigger and cycle in the presence of variable leaks. Auto-triggering is a common asynchrony during NIV and is related to the ventilator's leak-compensation performance.

\section{What this paper contributes to our knowledge}

The leak-compensation performance of ventilators used for pediatric NIV varied widely. Lung mechanics and model size significantly impacted leak compensation. In clinical practice, minimizing leak should be a primary goal.

dard circuit, if available, or a standard pediatric corrugated circuit (Hudson, Temecula, California). All of the ventilators were studied with a dry circuit: humidifiers and heat and moisture exchangers were removed.

\section{Study Setup}

The lung simulator was used to simulate 3 pediatric ventilation scenarios, with different lung sizes based on weight (10, 20, and $30 \mathrm{~kg}$ ) (Fig. 1). We modeled lung diseases by adjusting the airway resistance and lung compliance to represent a normal lung, an obstructive condition, and a restrictive condition. The inspiratory time of the simulator, the maximum inspiratory pressure drop, the airway-occlusion pressure $0.1 \mathrm{~s}$ after the start of inspiratory flow $\left(\mathrm{P}_{0.1}\right)$, and the breathing frequency in each scenario are summarized in Table 2. We chose these settings based on referenced values, pediatric and adult model studies, or measurements that we have commonly observed in the clinical setting for mechanically ventilated patients of these sizes..$^{13,16}$ In pressure support ventilation, the set peak-inspiratory-pressure-generated tidal volume was $7-10 \mathrm{~mL} / \mathrm{kg}$ in the normal model, for each body weight, with baseline leak. Peak inspiratory pressure was set at $15 \mathrm{~cm} \mathrm{H}_{2} \mathrm{O}$, and PEEP was set at $5 \mathrm{~cm} \mathrm{H}_{2} \mathrm{O}$, as described below. Two mannequin heads (bigger for the $30-\mathrm{kg}$ model and smaller for the $20-\mathrm{kg}$ and $10-\mathrm{kg}$ models) were used to simulate the patient-mask interface. Endotracheal tubes fitted into the mouth and nostrils directed gas coming from a mask to the simulator (see Fig. 1). These nasal and oral tubes met in a common airway leading to the Simulator Bypass and Leak Valve Module, which led to the lung simulator. The oronasal mask (PerformaTrack SE, Respironics, Murrysville, Pennsylvania) for the $30-\mathrm{kg}$ model was affixed to the head of the mannequin with standard 


\section{Leak Compensation During Pediatric Noninvasive Ventilation}

Table 1. Ventilators, Software, Leak Compensation Specifications, Sensitivity, Rise Time, and Expiratory Trigger Setting

\begin{tabular}{|c|c|c|c|c|c|}
\hline Ventilator & Software & $\begin{array}{c}\text { Leak } \\
\text { Compensation }\end{array}$ & Sensitivity & $\begin{array}{l}\text { Rise Time } \\
\text { Setting }\end{array}$ & $\begin{array}{c}\text { Expiratory } \\
\text { Trigger Setting } \\
\% \text { of inspiratory flow }\end{array}$ \\
\hline Servo-i & V5.00.00 & NIV: $50 \mathrm{~L} / \mathrm{min}$ & Not adjustable & $0 \mathrm{~ms}$ & 50 \\
\hline PB840 & 4-070212-85-AG & NIV: $65 \mathrm{~L} / \mathrm{min}$ & $1 \mathrm{~L} / \mathrm{min}$ & $100 \%$ & 25 \\
\hline $\mathrm{C} 3$ & 1.0 .0 & No information & $1 \mathrm{~L} / \mathrm{min}$ & $25 \mathrm{~ms}$ & $50-60$ \\
\hline G5 & $2.1 \mathrm{X}$ & No information & $1 \mathrm{~L} / \mathrm{min}$ & $25 \mathrm{~ms}$ & $50-60$ \\
\hline V500 & 2.23 & $180 \mathrm{~L} / \mathrm{min}$ & $1 \mathrm{~L} / \mathrm{min}$ & $0 \mathrm{~ms}$ & 25 \\
\hline CareStation & 5.0 & No information & $1 \mathrm{~L} / \mathrm{min}$ & $0 \mathrm{~ms}$ & 25 \\
\hline Avea & 4.4 & No information & $1 \mathrm{~L} / \mathrm{min}$ & 1 (fastest) & 45 \\
\hline Carina & $3 . n$ & $180 \mathrm{~L} / \mathrm{min}$ & Sensitive & $0.1 \mathrm{~s}$ & Sensitive \\
\hline V60 & PN 1076723 Auto-Track+ & $60 \mathrm{~L} / \mathrm{min}$ & +5 & 1 (fastest) & $\begin{array}{l}\text { Normal model: } 3 \\
\text { Obstruction model: } 5 \\
\text { Restriction model: normal }\end{array}$ \\
\hline Vision & 13.4 & $60 \mathrm{~L} / \mathrm{min}$ & Not adjustable & $0.05 \mathrm{~s}$ & Not adjustable \\
\hline
\end{tabular}

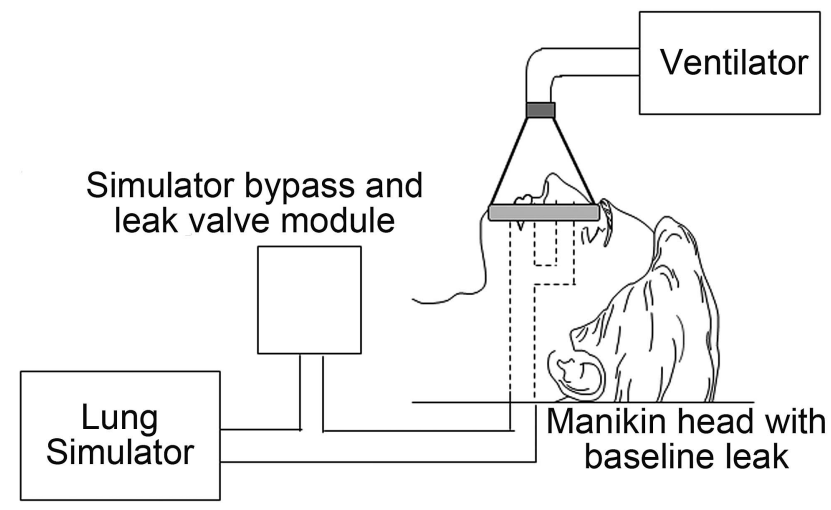

Fig. 1. Experimental setup for studying ventilator performance in pediatric noninvasive ventilation scenarios.

straps. A nasal mask (Contour Deluxe, Respironics, Murrysville, Pennsylvania) was used as an oronasal mask for both the 20-kg and 10-kg models. A baseline leak of approximately $2-3 \mathrm{~L} / \mathrm{min}$ (baseline [B] leak) at a mean airway pressure of $5 \mathrm{~cm} \mathrm{H}_{2} \mathrm{O}$ was established prior to each evaluation. The Simulator Bypass and Leak Valve Module was set to established leak flows of 5-6 L/min (leak level L1), 9-10 L/min (leak level L2), and 19-20 L/min (leak level L3) at a mean airway pressure of $5 \mathrm{~cm} \mathrm{H}_{2} \mathrm{O}$. All 6 combinations of increasing leak change $(\mathrm{B} \rightarrow \mathrm{L} 1, \mathrm{~B} \rightarrow \mathrm{L} 2$, $\mathrm{B} \rightarrow \mathrm{L} 3, \mathrm{~L} 1 \rightarrow \mathrm{L} 2, \mathrm{~L} 1 \rightarrow \mathrm{L} 3, \mathrm{~L} 2 \rightarrow \mathrm{L} 3)$ and all 6 decreasing leak changes $(\mathrm{L} 3 \rightarrow \mathrm{L} 2, \mathrm{~L} 3 \rightarrow \mathrm{L} 1, \mathrm{~L} 3 \rightarrow \mathrm{B}, \mathrm{L} 2 \rightarrow \mathrm{L} 1, \mathrm{~L} 2 \rightarrow \mathrm{B}$, $\mathrm{L} 1 \rightarrow \mathrm{B}$ ) were evaluated.

\section{Ventilator Settings}

During ventilator assessment, all ventilators were set in the NIV mode, as follows: pressure support mode, pres- sure support $10 \mathrm{~cm} \mathrm{H}_{2} \mathrm{O}$, PEEP $5 \mathrm{~cm} \mathrm{H}_{2} \mathrm{O}$, breathing frequency 4 breaths/min, leak compensation activated. Trigger sensitivity, when adjustable, was set to be as sensitive as possible while avoiding auto-triggering at baseline leak. Inspiratory rise time, when adjustable, was set to the most rapid setting while avoiding overshooting of the set peak pressure. Termination criteria, when adjustable, was set at $25 \%$ of peak flow. If delayed cycling occurred in the presence of leak, the termination criteria was adjusted to avoid delayed cycling, and the data were collected with these same settings through the study. The "normal" cycling setting with the dedicated NIV ventilators resulted in delayed cycling at baseline leak. With the Carina the triggering sensitivity and termination criteria were set at "sensitive." With the V60 the termination criteria were set to avoid delayed cycling. With the Vision neither triggering nor cycling is adjustable. The maximum inspiration time was set to $1.5 \mathrm{~s}$, if available. All ventilator settings are summarized in Table 1.

\section{Data Collection and Evaluation}

All combinations of increasing or decreasing leaks were sequentially added to the system. After each change in leak level we collected 2 min of data. The following variables were calculated:

Synchronization rate $(\%)=($ synchronized cycles/total simulated breathing frequency during $2 \mathrm{~min}) \times 100$

Auto-triggering rate $(\%)=$ (auto-triggered cycles/total simulated breathing frequency during $2 \mathrm{~min}) \times 100$

Miss-triggering rate $(\%)=($ miss-triggered cycles/total simulated breathing frequency during $2 \mathrm{~min}) \times 100$

Synchronization was defined as triggering without autotriggering, miss-triggering, delayed cycling, or premature 


\section{Leak Compensation During Pediatric Noninvasive Ventilation}

Table 2. Lung Model Settings

\begin{tabular}{|c|c|c|c|c|c|c|c|c|}
\hline Model* & $\begin{array}{l}\text { Lung } \\
\text { Mechanics }\end{array}$ & $\begin{array}{l}\text { Compliance } \\
\left(\mathrm{mL} / \mathrm{cm} \mathrm{H}_{2} \mathrm{O}\right)\end{array}$ & $\begin{array}{c}\text { Resistance } \\
\left.\text { (cm H } \mathrm{H}_{2} \mathrm{O} / \mathrm{L} / \mathrm{s}\right)\end{array}$ & $\begin{array}{c}\mathrm{P}_{0.1} \\
\left(\mathrm{~cm} \mathrm{H} \mathrm{H}_{2} \mathrm{O}\right)\end{array}$ & $\begin{array}{c}\mathrm{P}_{\max } \\
\left(\mathrm{cm} \mathrm{H} \mathrm{H}_{2} \mathrm{O}\right)\end{array}$ & $\begin{array}{l}\text { FRC } \\
(\mathrm{mL})\end{array}$ & $\begin{array}{c}\text { Breathing } \\
\text { Frequency } \\
\text { (breaths/min) }\end{array}$ & $\begin{array}{c}\text { Inspiratory } \\
\text { Time } \\
\text { (s) }\end{array}$ \\
\hline \multirow[t]{3}{*}{$10 \mathrm{~kg}$} & Normal & 10 & 25 & -2.8 & -4.0 & 300 & 30 & 0.46 \\
\hline & Obstructive & 10 & 50 & -2.8 & -4.0 & 600 & 30 & 0.46 \\
\hline & Restrictive & 5 & 25 & -2.8 & -4.0 & 150 & 30 & 0.46 \\
\hline \multirow[t]{3}{*}{$20 \mathrm{~kg}$} & Normal & 20 & 20 & -3.3 & -4.5 & 600 & 25 & 0.55 \\
\hline & Obstructive & 20 & 40 & -3.3 & -4.5 & 1,200 & 25 & 0.55 \\
\hline & Restrictive & 10 & 20 & -3.3 & -4.5 & 300 & 25 & 0.55 \\
\hline \multirow[t]{3}{*}{$30 \mathrm{~kg}$} & Normal & 30 & 15 & -3.9 & -5.0 & 900 & 20 & 0.69 \\
\hline & Obstructive & 30 & 30 & -3.9 & -5.0 & 1,500 & 20 & 0.69 \\
\hline & Restrictive & 15 & 15 & -3.9 & -5.0 & 450 & 20 & 0.69 \\
\hline \multicolumn{9}{|c|}{$\begin{array}{l}\text { * In pressure support ventilation the set peak inspiratory pressure generate } \\
\text { was set at } 15 \mathrm{~cm} \mathrm{H}_{2} \mathrm{O} \text {. PEEP was set at } 5 \mathrm{~cm} \mathrm{H}_{2} \mathrm{O} \text {. } \\
\mathrm{P}_{0.1} \text { = airway-occlusion pressure } 0.1 \mathrm{~s} \text { after the start of inspiratory flow } \\
\mathrm{P}_{\max }=\text { maximum negative muscle pressure } \\
\text { FRC = functional residual capacity }\end{array}$} \\
\hline
\end{tabular}

cycling. Ventilators that achieved a synchronization rate of $>90 \%$ were considered appropriate for pediatric NIV. ${ }^{16}$ Delayed cycling was defined as a cycling delay time (time from the end of the simulated inspiratory effort to the moment the ventilator cycled from inspiration to expiration) greater than 2 times the simulated inspiratory time. ${ }^{16}$ Premature cycling was defined as an inspiratory time of the ventilator less than half of the inspiratory time of the simulator. ${ }^{16}$

We calculated the triggering delay time as the time from the beginning of the inspiratory effort of the lung simulator to the maximum negative airway pressure deflection needed to trigger the ventilator and delivered tidal volume. Since a triggering delay time of approximately $15 \%$ of the inspiratory time was considered an acceptable range in adult model studies, ${ }^{13,17}$ we considered triggering delay times $<70,85$, and $105 \mathrm{~ms}$ for the 10,20 , and $30-\mathrm{kg}$ models, respectively, as acceptable values.

\section{Statistical Analysis}

After stabilization, 2 min of data were collected and 5 consecutive breaths were analyzed for cycling time, triggering delay time, and delivered tidal volume. Offline analysis of each breath was performed by the lung simulator's software (Labview, National Instruments, Austin, Texas). The results are presented as mean \pm SD or median (range) depending on the parametric or non-parametric nature of the data distribution. Analysis of variance and Bonferroni test for multiple comparisons were used for overall comparisons between ventilators, for comparisons of lung mechanics within each ventilator, and for comparisons of each body weight and leak level within each ventilator and across ventilators. Statistical analysis was done with sta- tistics software (PASW Statistic 18, SPSS, Chicago, Illinois). $P<.05$ was considered significant, but we discuss only differences that were both statistically significant and $>10 \%$.

\section{Results}

\section{Synchronization}

The mean synchronization rate across all the ventilators was $68 \pm 27 \%$ (range 23-96\%). Significant differences in synchronization rate were observed between the $10-\mathrm{kg}$ (mean $57 \pm 30 \%$, range 17-93\%), the $20-\mathrm{kg}(69 \pm 30 \%$, $25-98 \%)$, and the 30-kg models $(77 \pm 22 \%, 28-97 \%)$ $(P<.001)$ (Fig. 2). The synchronization rate of the obstructive model $(60 \pm 30 \%, 9-94 \%)$ was significantly different from that of the normal model $(71 \pm 29 \%, 18-$ $98 \%)$ and restrictive model $(72 \pm 28 \%, 23-98 \%)(P<.001)$ (see Fig. 2). As leak increased, the mean synchronization rate decreased (B $88 \pm 9 \%$, range $68-100 \%, \mathrm{~L} 169 \pm 32 \%$, 6-99\%, L2 $64 \pm 35 \%, 0-97 \%$, L3 $51 \pm 39 \%, 0-94 \%)$ (see Fig. 2). The synchronization rate was lower and autotriggering was higher with increasing leak than with decreasing leak $(P<.001)$ (see the supplementary materials at http://www.rcjournal.com).

\section{Comparison of Ventilators}

The PB840 and the C3 had synchronization rates of over $90 \%$ with all body weights, all lung mechanics profiles, and all leak levels (see Fig. 2). In the 10-kg model, the PB840 and C3 had synchronization rates above $90 \%$ overall across all the lung mechanics profiles, but no ventilators had a synchronization rate over $90 \%$ in the obstructive model alone (PB840 87\%, C3 89\%). With the 

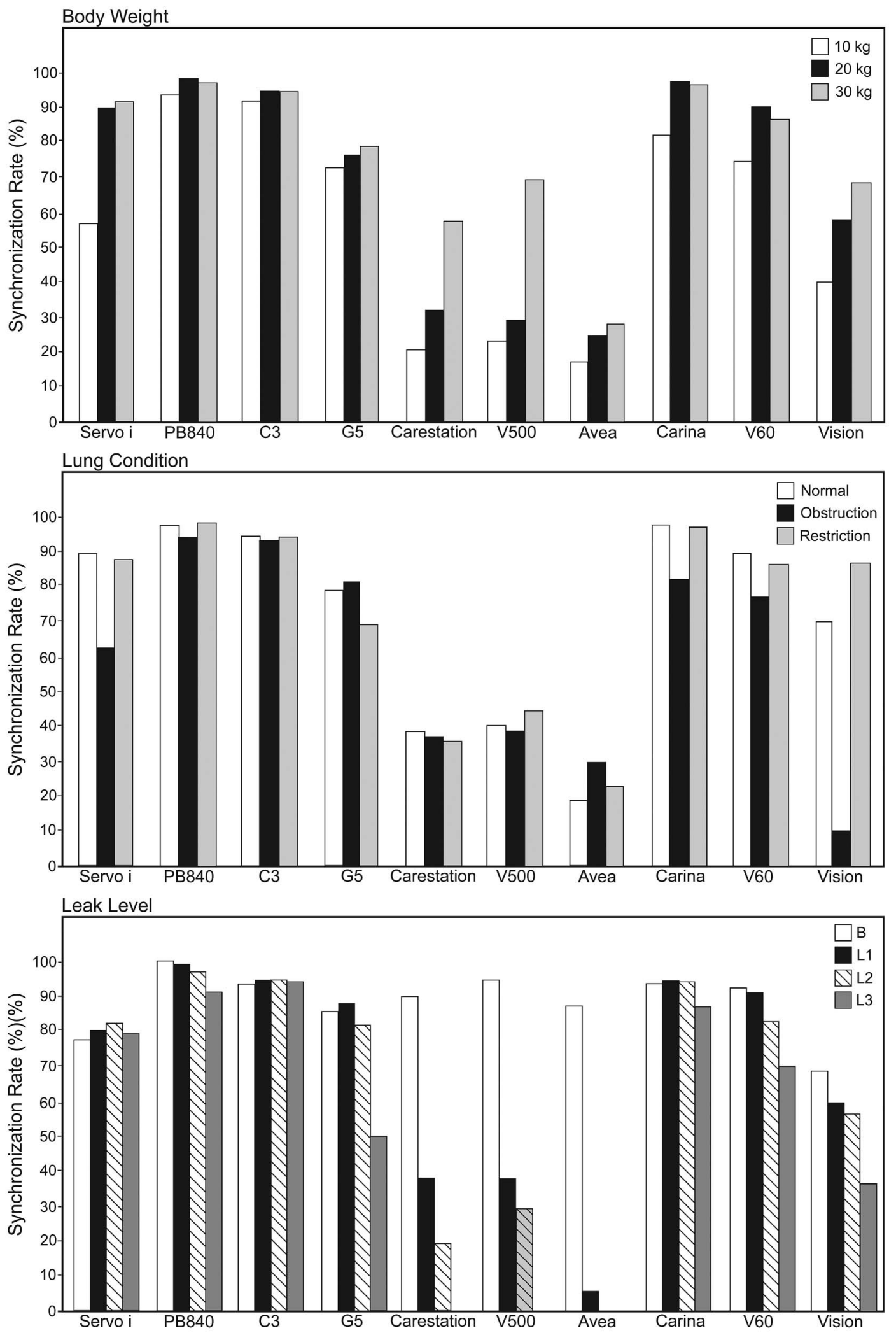

Fig. 2. Synchronization rates with 3 simulated body weights $(10,20$, and $30 \mathrm{~kg}$ ), 3 lung mechanics conditions (normal, obstructive, and restrictive), and 4 leak levels: baseline $(\mathrm{BL})$ 2-3 L/min, L1 5-6 L/min, L2 9-10 L/min, and L3 19-20 L/min. Synchronization rate increased with body weight $(P<.001)$. Synchronization rates were lower in the obstructive model than in the normal and the restrictive models $(P<.001)$. As leak increased, synchronization rate decreased $(P<.001)$. The bars show mean values. 


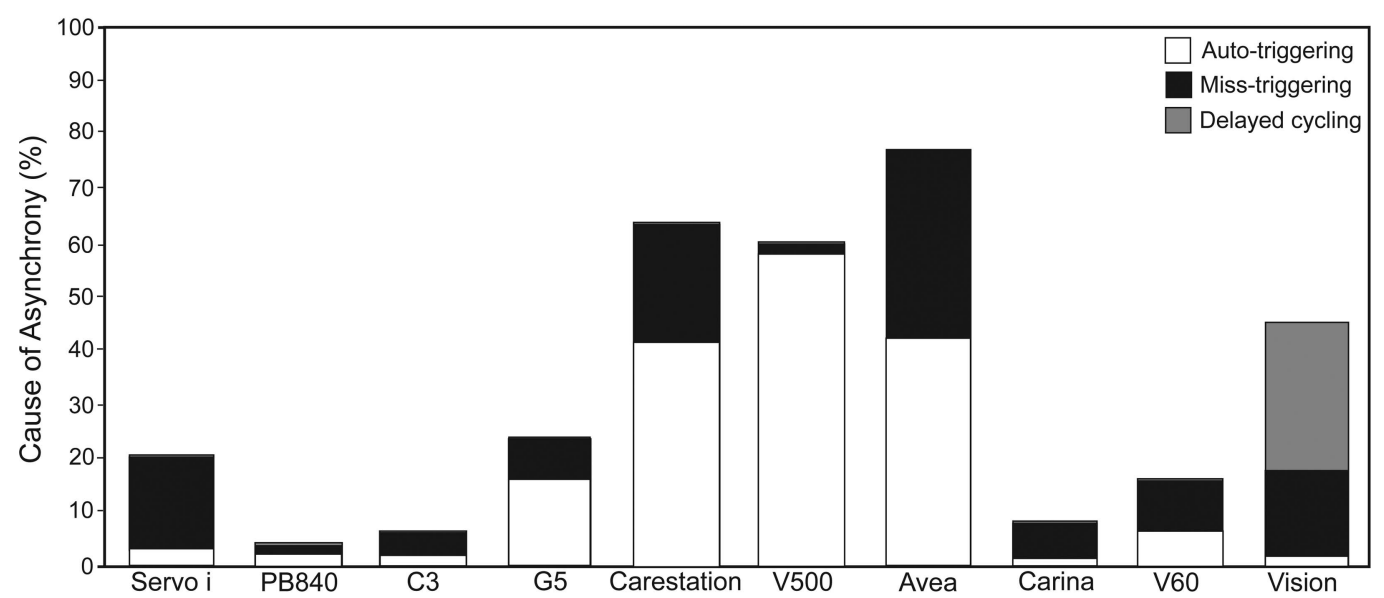

Fig. 3. Types of asynchrony (auto-triggering, missed-triggering, and delayed cycling) as a percentage of the total simulated breaths. Premature cycling is not shown because it occurred only with the PB840 and in $<0.1 \%$ of simulated breaths. The bars show mean values.

20-kg model the Servo-i, PB840, C3, Carina, and V60 had synchronization rates over $90 \%$ (see Fig. 2). In the $30-\mathrm{kg}$ model the same ventilators as in the $20-\mathrm{kg}$ model, except for the V60, had synchronization rates over $90 \%$ (see Fig. 2).

\section{Types of Asynchrony}

The Servo-i, C3, G5, and Avea tended to have prolonged inspiratory time at a cycling criteria of $25 \%$ of peak inspiratory flow. Thus, these ventilators were managed using the cycling criteria at $45-60 \%$ of peak inspiratory flow (see the supplementary materials at http://www.rc journal.com). On the other hand, the PB840, Carestation, and V500 did not have prolonged inspiratory time at 25\% of peak inspiratory flow, but values of the cycling criteria over $25 \%$ induced shorter inspiratory time than the lung

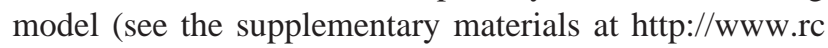
journal.com). Among all the ventilators, auto-triggering occurred in $54 \%$ of the total asynchronies, miss-triggering in $37 \%$, and delayed cycling in $9 \%$. Except for the Vision, the rate of delayed cycling was under $1 \%$ of the total simulated breaths. Premature cycling was seen only with the PB840 (0.02\% of total simulated breaths). The causes of the asynchronies are summarized in Figure 3.

In the obstructive model, auto-triggering was less frequent than in the normal and restrictive models $(P<.001)$ (Fig. 4). As leak increased, the rate of auto-triggering increased $(P<.001)$ (see Fig. 4). In the obstructive model, miss-triggering was more frequent than in the normal and restrictive models $(P<.001)$ (Fig. 5). As body weight decreased, miss-triggering increased $(P<.001)$ (see Fig. 5).

\section{Triggering Delay Time}

The mean triggering delay time was longer in the obstructive model $(107 \pm 20 \mathrm{~ms})$ than in the normal $(87 \pm 21$ ms) and restrictive models $(81 \pm 18 \mathrm{~ms})(P<.001)$. As leak increased, the mean triggering delay time increased (B $87 \pm 18 \mathrm{~ms}$, L1 $88 \pm 20 \mathrm{~ms}, \mathrm{~L} 292 \pm 20 \mathrm{~ms}$, L3 $105 \pm 23 \mathrm{~ms}, P<.001)$. The Servo-i and Vision had mean triggering delays over $100 \mathrm{~ms}$ (Servo-i $116 \pm 15 \mathrm{~ms}$, Vision $107 \pm 8 \mathrm{~ms}$ ) (see the supplementary materials at http://www.rcjournal.com). In the 10-kg model, all the ventilators had triggering delays over the acceptable range $(<70 \mathrm{~ms})$, except during baseline leak.

\section{Tidal Volume}

Significant differences in tidal volume were observed between the $10-\mathrm{kg}$ (median $70 \pm 15 \mathrm{~mL}$ ), 20-kg $(126 \pm 27 \mathrm{~mL})$, and $30-\mathrm{kg}$ models $(187 \pm 46 \mathrm{~mL})(P<.001)$ (see the supplementary materials at http://www.rcjournal. com). The mean tidal volume was larger in the normal model $(169 \pm 63 \mathrm{~mL})$ than in the obstructive $(123 \pm 45 \mathrm{~mL})$ and restrictive models $(112 \pm 42 \mathrm{~mL})(P<.001)$. As leak increased, tidal volume decreased (median B $139 \pm 58 \mathrm{~mL}$, $\mathrm{L} 1136 \pm 57 \mathrm{~mL}, \mathrm{~L} 2130 \pm 54 \mathrm{~mL}, \mathrm{~L} 3115 \pm 50 \mathrm{~mL}$, $P<.001$ ) (see the supplementary materials at http:// www.rcjournal.com).

\section{Discussion}

Our main findings are:

- Smaller patient size, obstructive lung mechanics, and higher system leak decrease these ventilators' ability to synchronize during simulated pediatric NIV.

- Triggering asynchrony was more common than cycling asynchrony.

- Auto-triggering increased with larger system leak and decreased with the obstructive lung model. 

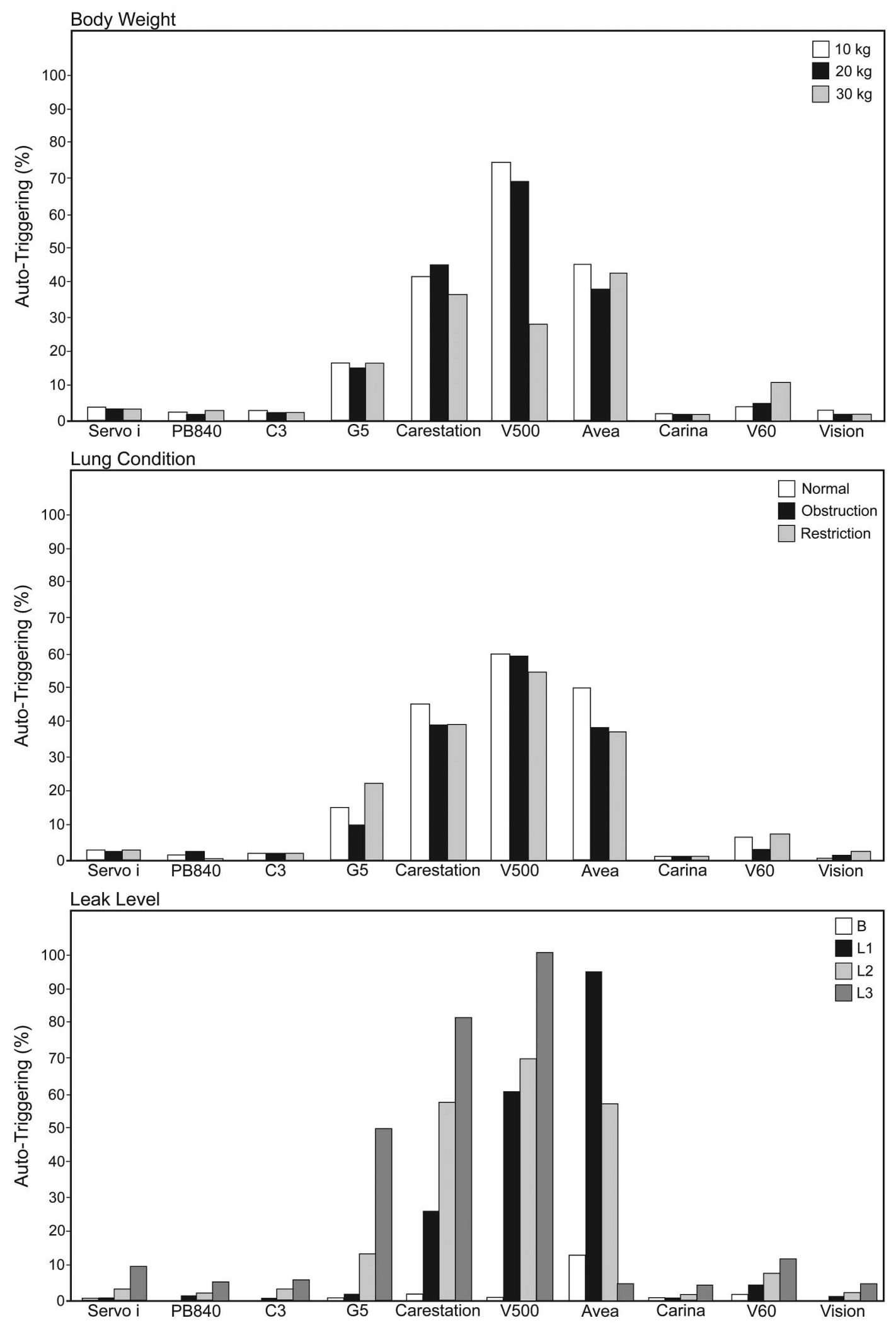

Fig. 4. Percentage of simulated breaths that had auto-triggering, relative to body weight, lung mechanics scenario, and leak level (as in Fig. 3). Auto-triggering rate were not associated with body weight $(P=.10)$. Auto-triggering was lower in the obstructive model than in the normal and restrictive models $(P<.001)$. As leak increased, auto-triggering rate increased $(P<.001)$. The bars show mean values. 


\section{Leak Compensation During Pediatric Noninvasive Ventilation}
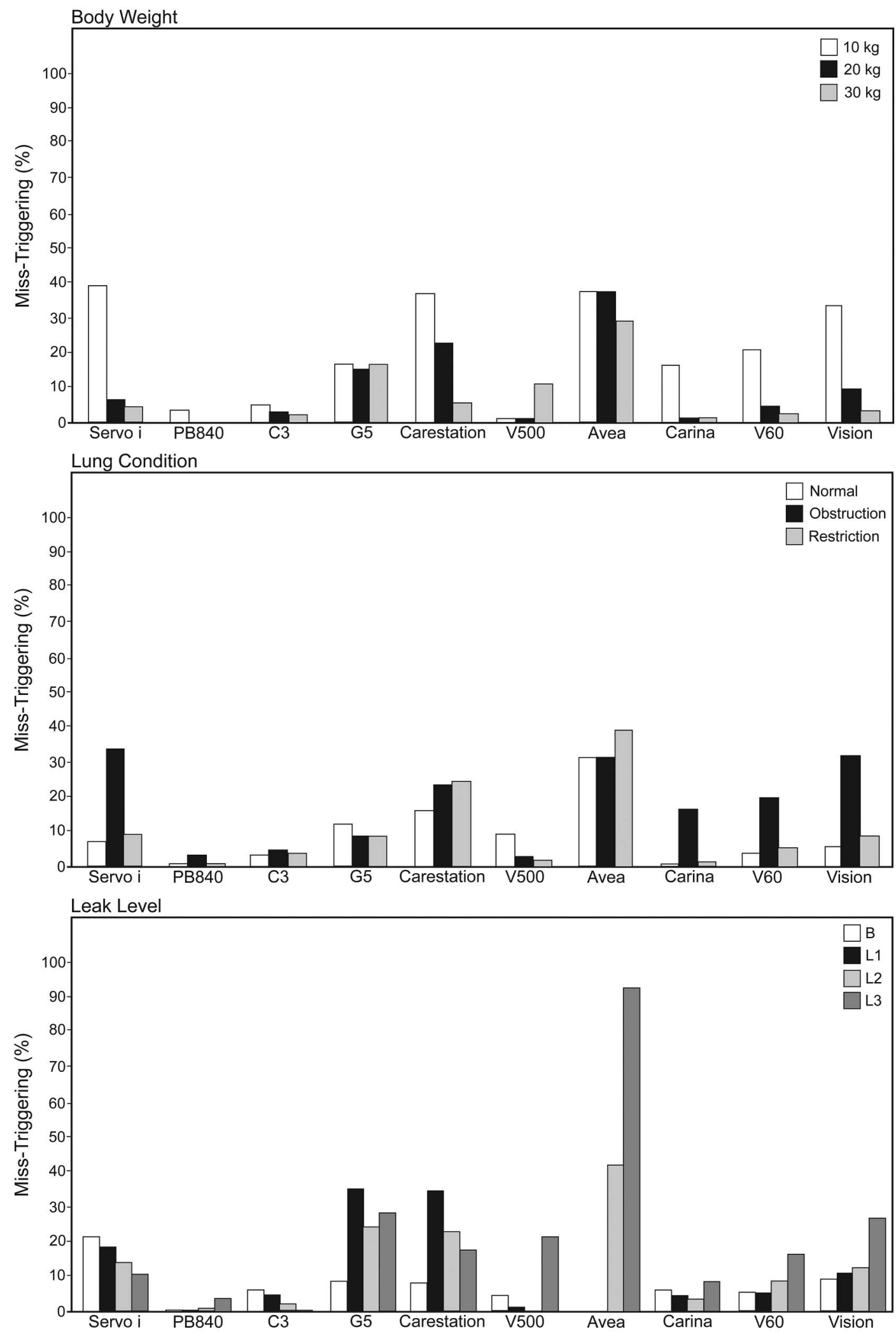

Fig. 5. Percentage of simulated breaths that had miss-triggering, relative to body weight, lung mechanics scenario, and leak level (as in Fig. 3). Miss-triggering increased with decreased body weight $(P<.001)$. Miss-triggering was higher in the obstructive model than in the normal and restrictive models $(P<.001)$. Miss-triggering was not associated with leak level $(P=.06)$. The bars show mean values. 


\section{Leak Compensation During Pediatric Noninvasive Ventilation}

- Miss-triggering increased with smaller patient size and with the obstructive lung model.

- These ventilators performed better during decreasing leak than increasing leak.

- There were wide differences between these ventilators in ability to synchronize.

- The PB840 and the C3 had synchronization rates over $90 \%$ overall across all body weights, lung mechanic profiles, and leak levels. This is the first bench study to evaluate the performance of leak compensation among acute care ventilators for 9 different pediatric patient profiles: 3 patient sizes, 3 lung mechanics scenarios, and 3 leak levels.

As patient size increased, the ventilators showed better synchronization with the lung simulator. In the $10-\mathrm{kg}$ model the inspiratory efforts were smaller, which reduced these ventilators' ability to detect the onset of inspiration and expiration. In addition, the airway resistance was higher in the $10-\mathrm{kg}$ model than in the $20-\mathrm{kg}$ and $30-\mathrm{kg}$ models, which also impaired triggering and led to miss-triggering and delayed cycling. Miss-triggering was more frequent with the lower body weight and obstructive conditions.

The limitations of pressure-targeted ventilators during NIV in small children are well documented in recent clinical $^{9}$ and bench studies. ${ }^{10}$ Essouri et al reported that all patients $<10 \mathrm{~kg}$ showed marked patient-ventilator asynchrony (ineffective inspiratory efforts ranging from $32 \%$ to $97 \%$ of inspiratory efforts), and $33 \%$ of patients over $10 \mathrm{~kg}$ also showed patient-ventilator asynchrony. ${ }^{9}$ In a bench study, Fauroux et al evaluated the performance of 17 home ventilators during NIV, with several pediatric profiles, and found that none of the tested ventilators synchronized well with every patient profile, and that the more sensitive a ventilator was to leaks, the less responsive it was to patient triggering efforts, especially with the smallest patient size. ${ }^{10}$

In our obstructive model, miss-triggering was more frequent than in the normal and restrictive models. Compared to the normal and restrictive models, the obstructive model showed increased triggering delay time. These results are consistent with those of previous reports. ${ }^{16,18}$ This may be explained by the presence of a higher airway resistance, which impedes the transmission of respiratory efforts to the ventilator and requires larger efforts to reach the trigger threshold, due to higher pressures throughout the airway.

The ventilators performed better during decreasing than increasing leak. As system leak increased, the ventilators misinterpreted the resulting changes in flow as inspiratory efforts, leading to frequent auto-triggering. Vignaux et al found that in patients showing auto-triggering the magnitude of leak was higher than those not showing it. However, they found no correlation between leak volume and the severity of auto-triggering. ${ }^{19} \mathrm{~A}$ possible reason for the difference is that our simulated leak levels had a wider range (from $3-4 \mathrm{~L} / \mathrm{min}$ to $19-20 \mathrm{~L} / \mathrm{min}$ ) than the previous study $^{19}$ (up to $6.1 \mathrm{~L} / \mathrm{min}$ ). Also, in our study some ventilators could not synchronize in the presence of larger leaks, especially $9-10 \mathrm{~L} / \mathrm{min}$ and $19-20 \mathrm{~L} / \mathrm{min}$, mainly due to auto-triggering. Another reason was that we tested 10 different ventilators. The frequency of auto-triggering depends on the ventilator performance, as described in previous studies. ${ }^{13,14,17,20}$ Auto-triggering was less frequent in the obstructive model than the normal or restrictive models, and this concurs with previous reports. ${ }^{21-23}$

Most acute care ventilators have cycling systems based on a preset flow threshold. System leak prevents the air flow from reaching the preset expiratory cycling flow, leading to a prolonged inspiratory time and patient-ventilator asynchrony. ${ }^{8}$ This study showed that delayed cycling was not the main cause of patient-ventilator asynchrony in the presence of system leak, if the termination criteria were adjustable. However, appropriate cycling criteria seemed to be different between ventilators. Regarding the ICU ventilators, the Servo-i, C3, G5, and Avea tended to prolong inspiratory time at cycling criteria of $25 \%$ of peak inspiratory flow, but cycled appropriately at $50-60 \%$ of peak inspiratory flow (see the supplementary materials at http://www.rcjournal.com). On the other hand, with the PB840, Carestation, and V500, 25\% of peak inspiratory flow was better than $50-60 \%$ in the restrictive model (see the supplementary materials at http://www.rcjournal.com). With the dedicated NIV ventilators, if the "normal" cycling setting was used, these 3 ventilators showed delayed cycling, especially in the normal and obstructive models. Dedicated NIV ventilators transition to exhalation primarily by what is referred to as a shape signal, and tend to prolong inspiratory time, compared with ICU ventilators. Adjustable sensitivity of the inspiratory and expiratory triggers is of great importance in both dedicated NIV ventilators and ICU ventilators for pediatric use. Because the Vision has a fixed inspiratory and expiratory flow-trigger, delayed cycling occurred frequently. In that situation it may be better to use time-cycled criteria to avoid delayed cycling. ${ }^{24}$

Our study indicates that the leak compensation on acute care ventilators can correct partially or completely for system leak interferences in pediatric lung simulations, but there was wide variation among the ventilators. In general, the PB840, C3, and Carina had synchronization rates of over $90 \%$. Vignaux et al performed a bench study of 8 ICU ventilators with leak compensation. ${ }^{14}$ On most of the tested ventilators, leak increased trigger delay, decreased the ability to reach the pressure target, and delayed cycling. Similar to our findings, they found that the NIV mode partially or completely corrected for triggering and cycling delay, and there was marked variation among ventilators. ${ }^{14}$ Since 


\section{Leak Compensation During Pediatric Noninvasive Ventilation}

the manufacturers do not disclose the exact triggering and cycling algorithms for leak compensation, it is impossible to explain the wide variations in synchronization ability among the ventilators tested.

Regarding trigger delay, most ventilators, except for the Servo-i and Vision, showed triggering delay times lower than the predefined acceptable values in the $20-\mathrm{kg}$ and $30-\mathrm{kg}$ models. However, no ventilator achieved a triggering delay time lower than the predefined acceptable values in the 10-kg model. Because a prolonged trigger delay may lead to an increase of patient work of breathing and patient-ventilator asynchrony, further technical improvements are needed to ensure appropriate application of NIV to pediatric patients under $10 \mathrm{~kg}$.

The primary limitation of this study is that the study was not conducted on patients, which raises the question of the extent to which the findings may be clinically relevant. Although we used a sophisticated lung model, this is not the same as an actual patient's respiratory system. In clinical settings, breathing frequency, inspiratory time, $\mathrm{P}_{0.1}$, and $\mathrm{P}_{\max }$ may be different among patients with normal, obstructive, and restrictive lung mechanics. However, we mainly focused on the effects of different lung compliance, airway resistance, and patient weight on the ventilators' synchronization ability. In mechanically ventilated children Harikumar et al measured a $\mathrm{P}_{0.1}$ of $-2.4 \mathrm{~cm} \mathrm{H}_{2} \mathrm{O}$ (range -0.9 to $-6.1 \mathrm{~cm} \mathrm{H}_{2} \mathrm{O}$ ). ${ }^{25} \mathrm{~A}$ breathing effort of -2.8 to $-3.9 \mathrm{~cm} \mathrm{H}_{2} \mathrm{O}$ (the values we chose in this study) probably correspond to the median effort for pediatric patients who required mechanical ventilation. In addition, lung simulator studies assure that experimental conditions are the same for each ventilator evaluated. It is impossible, especially in pediatric patients, to control the level of the leak or maintain stable baseline conditions in clinical settings. Another limitation is that we tested only a limited range of leaks and ventilator settings. However, we chose these to represent the range of NIV leak flows likely to be encountered in clinical settings. In addition, we were interested in evaluating the maximum capabilities of the ventilators tested.

\section{Conclusions}

Leak readily leads to patient-ventilator asynchrony, especially in small pediatric patients. Clinicians should try to decrease leak as much as possible. All of the acute care ventilators we tested adequately synchronized with simulated ventilatory efforts at baseline, and some ventilators synchronized well with high leaks, but there were wide variations among the ventilators. The performance of all ventilators was strongly affected by the patient profile, including body size and underlying lung mechanics. Clinicians should be aware of these differences when applying leak compensation during NIV, especially in children. Although the PB840 and the C3 showed better synchrony with triggering and cycling than the other ventilators, the clinical importance of these differences is unclear. Further studies are needed to determine the impact of different ventilators on the outcome of different groups of patients receiving NIV.

\section{REFERENCES}

1. Hill NS, Brennan J, Garpestad E, Nava S. Noninvasive ventilation in acute respiratory failure. Crit Care Med 2007;35(10):2402-2407.

2. Calderini E, Chidini G, Pelosi P. What are the current indications for noninvasive ventilation in children? Curr Opin Anesthesiol 2010; 23(3):368-374.

3. Marcus CL, Rosen G, Ward SL, Halbower AC, Sterni L, Lutz J, et al. Adherence to and effectiveness of positive airway pressure therapy in children with obstructive sleep apnea. Pediatrics 2006;117(3): e442-e451.

4. Gupta P, Kuperstock JE, Hashmi S, Arnolde V, Gossett JM, Prodhan $\mathrm{P}$, et al. Efficacy and predictors of success of noninvasive ventilation for prevention of extubation failure in critically ill children with heart disease. Pediatr Cardiol 2013;34(4):964-977.

5. Stucki P, Perez MH, Scalfaro P, de Halleux Q, Vermeulen F, Cotting J. Feasibility of non-invasive pressure support ventilation in infants with respiratory failure after extubation: a pilot study. Intensive Care Med 2009;35(9):1623-1627.

6. Piastra M, De Luca D, Pietrini D, Pulitanò S, D'Arrigo S, Mancino A, Conti G. Noninvasive pressure-support ventilation in immunocompromised children with ARDS: a feasibility study. Intensive Care Med 2009;35(8):1420-1427.

7. Mellies U, Ragette R, Dohna Schwake C, Boehm H, Voit T, Teschler H. Long-term noninvasive ventilation in children and adolescents with neuromuscular disorders. Eur Respir J 2003;22(4):631-636.

8. Fauroux B, Piqeot J, Polkey MI, Isabey D, Clément A, Lofaso F. In vivo physiologic comparison of two ventilators used for domiciliary ventilation in children with cystic fibrosis. Crit Care Med 2001; 29(11):2097-2105.

9. Essouri S, Durand P, Chevret L, Haas V, Perot C, Clement A, et al. Physiological effects of noninvasive positive ventilation during acute moderate hypercapnic respiratory insufficiency in children. Intensive Care Med 2008;34(12):2248-2255.

10. Fauroux B, Leroux K, Desmarais G, Isabey D, Clément A, Lofaso F, Louis B. Performance of ventilators for noninvasive positivepressure ventilation in children. Eur Respir J 2008;31(6):1300-1307.

11. Teague WG. Non-invasive positive pressure ventilation: current status in paediatric patients. Paediatr Respir Rev 2005;6(1):52-60.

12. Hess DR. Patient-ventilator interaction during noninvasive ventilation. Respir Care 2011;56(2):153-165.

13. Ferreira JC, Chipman DW, Hill NS, Kacmarek RM. Bilevel vs ICU ventilators providing noninvasive ventilation: effect of system leaks: a COPD lung model comparison. Chest 2009;136(2):448-456.

14. Vignaux L, Tassaux D, Jolliet P. Performance of noninvasive ventilation modes on ICU ventilators during pressure support: a bench study. Intensive Care Med 2007;33(8):1444-1451.

15. IngMar Medical. ASL5000 Active Servo Lung Computerized Breathing Simulator and Ventilator Test Instrument user's manual. Pittsburgh: IngMar Medical: 2006.

16. Thille AW, Rodriguez P, Cabello B, Lellouche F, Brochard L. Patient-ventilator asynchrony during assisted mechanical ventilation. Intensive Care Med 2006;32(10):1515-1522.

17. Carteaux G, Lyazidi A, Cordoba-Izquierdo A, Vignaux L, Jolliet P, Thille AW, et al. Patient-ventilator asynchrony during noninvasive ventilation: a bench and clinical study. Chest 2012;142(2):367-376.

18. Chao DC, Scheinborn DJ, Stearn-Hassenpflug M. Patient-trigger asynchrony in prolonged mechanical ventilation. Chest 1997;112(6): 1592-1599. 


\section{Leak Compensation During Pediatric Noninvasive Ventilation}

19. Vignaux L, Vargas F, Roeseler J, Tassaux D, Thille AW, Kossowsky MP, et al. Patient-ventilator asynchrony during non-invasive ventilation for acute respiratory failure: a multicenter study. Intensive Care Med 2009;35(5):840-846.

20. Oto J, Chenelle CT, Marchese AD, Kacmarek RM. A comparison of leak compensation in acute care ventilators during non-invasive and invasive ventilation: a lung model study. Respir Care 2013;58(12): 2027-2037.

21. Imanaka H, Nishimura M, Takeuchi M, Kimball WR, Yahagi N, Kumon K. Autotriggering caused by cardiogenic oscillation during flowtriggered mechanical ventilation. Crit Care Med 2000;28(2):402-407.

22. Prinianakis G, Delmastro M, Carlucci A, Ceriana P, Nava S. Effect of varying the pressurization rate during noninvasive pressure support ventilation. Eur Respir J 2004;23(2):314-320.

23. Hill LL, Pearl RG. Flow triggering, pressure triggering, and autotriggering during mechanical ventilation. Crit Care Med 2000;28(2): 579-581.

24. Calderini E, Confalonieri M, Puccio PG, Francavilla N, Stella L, Gregoretti C. Patient-ventilator asynchrony during noninvasive ventilation: the role of expiratory trigger. Intensive Care Med 1999; 25(7):662-667.

25. Harikumar G, Moxham J, Greenough A, Rafferty GF. Measurement of maximal inspiratory pressure in ventilated children. Pediatr Pulmonol 2008;43(11):1085-1091. 